\title{
Germinação de sementes de alface sob altas temperaturas.
}

\author{
Warley Marcos Nascimento ${ }^{1}$; Daniel J. Cantliffe ${ }^{2}$ \\ ${ }^{1}$ Embrapa Hortaliças, C. Postal 218, 70.359-970 Brasília-DF; ${ }^{2}$ Horticultural Sciences Department, University of Florida, P.O. Box \\ 110690, Gainesville, F1 32611-0690, USA. Email: wmn@cnph.embrapa.br
}

\section{RESUMO}

Altas temperaturas durante a embebição das sementes de alface podem inibir a germinação. Vários métodos para reduzir o problema da termoinibição e, ou termodormência têm sido propostos, incluindo a utilização de germoplasmas tolerantes, o ajuste do ambiente de produção de sementes, a utilização de reguladores de crescimento e o condicionamento osmótico das sementes. Nestas metodologias, o mecanismo de ação parece estar relacionado com o "enfraquecimento" ("amolecimento") do endosperma, que possibilitará o crescimento do embrião sob altas temperaturas. O enfraquecimento do endosperma, tem sido associado com a indução da enzima endo-b-mananase na região da micrópila. O etileno, também pode estar envolvido no controle desse processo.

\begin{abstract}
Lettuce seed germination at high temperature.

High temperature during imbibition of lettuce seeds can inhibit germination. Several methods to circumvent thermoinhibition and, or thermodormancy have been proposed including resistant germplasm, adjusting the seed production environment, the use of growth hormones and seed priming. The mechanism of action for each of these methodologies appears to be related specifically to endosperm loosening which allows the embryo to grow under high temperature. Endosperm loosening has been associated with the induction of endo-b-mannanase at the micropylar end. Ethylene may also play an important role in controlling this process.
\end{abstract}

Palavras-chave: Lactuca sativa, endosperma, atividade enzimática, condicionamento osmótico, estabelecimento de plântulas.
Keywords: Lactuca sativa, endosperm, enzyme activity, seed priming, stand establishment.

(Aceito para publicação em 17 de janeiro de 2.002)

\begin{abstract}
A lface (Lactuca sativa L.) é uma importante folhosa cultivada em várias partes do mundo. No Brasil, o cultivo da alface é realizado durante o ano todo, em diferentes regiões. Em condições de altas temperaturas, a semente (aquênio) de alface, quando semeada tanto em estufas (produção de mudas para o transplantio) quanto no campo (semeadura direta), poderá ter uma redução na germinação ou uma desuniformidade na emergência das plântulas. Estes fatos poderão reduzir a produtividade e consequentemente o lucro do produtor.
\end{abstract}

A temperatura, tem grande influência na germinação de sementes de alface. A temperatura ótima está em torno de $20^{\circ} \mathrm{C}$, e a maioria das cultivares não germina em temperaturas superiores a $30^{\circ} \mathrm{C}$. Quando condições de altas temperaturas ocorrem durante a embebição das sementes de alface, dois diferentes fenômenos podem ser observados: a) a termoinibição, que é um processo reversível, uma vez que a germinação ocorre quando a temperatura reduz para um nível adequado, e; b) a termodormência, onde as sementes não germinarão após a redução da temperatura, também chamada de dormência secundária (Khan, 1980/81). Neste caso, entretanto, a germinação ocorrerá se as sementes forem tratadas com reguladores de crescimento ou sumetidas ao condicionamento osmótico ("seed priming").

A temperatura máxima e crítica para a germinação das sementes de alface depende do genótipo (Harrington \& Thompson, 1952; Gray, 1975; Thompson et al., 1979; Damania, 1986). Algumas cultivares de alface podem germinar em temperaturas variando de 5 a $33^{\circ} \mathrm{C}$ (Gray, 1975). Em geral, temperaturas acima de $30^{\circ} \mathrm{C}$ afetam a germinação das sementes, reduzindo a velocidade ou a porcentagem de germinação. Assim, dependendo do local e época de semeadura, a germinação das sementes pode ser errática ou nula, comprometendo o estande no campo e, ou na casa de vegetação.

Diferentes estratégias para reduzir os problemas da termoinibição e, ou da termodormência têm sido utilizadas. Alguns genótipos termotolerantes têm sido identificados (Bradford, 1985) ou desenvolvidos (Guzman et al., 1992). Entretanto, efeitos ambientais na expressão do caráter de termotolerância têm sido observados (Nagata, 1997, comunicação pessoal $)^{1}$. Além deste fato, ainda não se entende como as sementes herdam a capacidade para germinarem em altas temperaturas.

Fatores ambientais durante a maturação das sementes também influenciam a temperatura limite de germinação. Durante o desenvolvimento das sementes, a temperatura pode afetar subseqüentemente a germinação (Gray et al., 1988; Drew \& Brocklehurst, 1990; Steiner \& Opoku-Boateng, 1991). Assim, sementes de alface produzidas em regiões de clima quente germinaram melhor em altas temperaturas (Harrington \& Thompson, 1952; Damania, 1986). Sob condições controladas, Gray et al. (1988) verificaram que as sementes de alface produzidas em regimes de temperatura de $30 / 20^{\circ} \mathrm{C}$ ger-

\footnotetext{
${ }^{1}$ Nagata, R.T. (Horticultural Sciences Department, University of Florida, P.O. Box 110690, Ginesville, Fl 32611-0690, USA).
} 
minaram melhor a $30^{\circ} \mathrm{C}$ do que sementes produzidas a $25 / 15^{\circ} \mathrm{C}$ ou $20 / 10^{\circ} \mathrm{C}$. Em outro estudo, Sung et al. (1998a) verificaram que sementes de alface produzidas a $30 / 20^{\circ} \mathrm{C}$ apresentaram uma maior porcentagem de germinação comparada com aquelas produzidas em condições de baixas temperaturas. Estes autores concluíram que o caráter de termo-tolerância foi regulado pela interação genótipo e temperatura durante o desenvolvimento das sementes.

$\mathrm{O}$ condicionamento osmótico das sementes pode diminuir o período entre a semeadura e o estabelecimento de plântulas e reduzir o risco das sementes expostas às condições adversas e fatores bióticos no campo durante esse período crítico de germinação. Em alface, esse tratamento tem sido utilizado, com sucesso, para reduzir o problema de inibição da germinação causado por temperaturas altas (Guedes \& Cantliffe, 1980; Khan, 1980/81; Guedes et al., 1981; Valdes et al., 1985; Wurr \& Felows, 1984; Nascimento \& Cantliffe, 1998). Entretanto, o mecanismo exato do condicionamento osmótico para a germinação das sementes de alface, nessas condições, não é totalmente conhecido.

A aplicação de reguladores de crescimento, como etileno, têm aumentado significativamente a germinação das sementes, sob altas temperaturas, em laboratório. Assim, a aplicação de precursores de etileno ou produtos à base de etileno têm permitido a germinação de sementes de alface em altas temperaturas (Saini et al. ,1986; Fu \& Yang, 1983; Khan \& Prusinski, 1989; Nascimento et al. , 1999c; 1999b; Nascimento, 2000). Neste aspecto, vale salientar que o uso de etileno não tem sido aplicado comercialmente.

É sabido que alto vigor e elevada germinação são dois pré-requisitos para se alcançar um bom estabelecimento de plântulas. Alto vigor das sementes é uma condição necessária para tolerar estresses ambientais (Heydecker, 1972), incluindo temperaturas. Foi sugerido recentemente, que o envelhecimento das sementes de alface reduz a capacidade para germinar em altas temperaturas (Nascimento et al., 1999a).

Os processos fisiológicos e bioquímicos que controlam a dormência de sementes e o possível mecanismo da germinação das sementes de alface, principalmente sob condições de altas temperaturas, não são totalmente bem entendidos. Nas ultimas décadas, dezenas de publicações têm sido dedicadas à explicação das razões por que as sementes de alface não germinam em determinadas condições e, ou, quais tratamentos permitem a germinação (Cantliffe et al., 2000).

Estudos sobre os efeitos de altas temperaturas na germinação de sementes de alface têm sido reportados há vários anos (Borthwick \& Robbins, 1928), e têm sido um tópico de grande interesse para vários pesquisadores (Cantliffe et al., 2000). Diferentes hipóteses foram enunciadas como causas da não germinação das sementes de alface: a) redução da permeabilidade do tegumento à trocas gasosas (Borthwick \& Robbins, 1928); b) impermeabilidade do tegumento à água (Speer, 1974); c) acumulação de produtos metabólicos no endosperma e embrião (Borthwick \& Robbins, 1928); d) efeitos inibitórios do ácido abscísico (McWha, 1976); e) mau funcionamento do fitocromo (Scheibe \& Lang, 1969); f) barreira física do tegumento e, ou endosperma (Ikuma \& Tilmann, 1963); g) inibição da secreção de enzimas da parede celular (Ikuma \& Tilmann, 1963; Dutta et al., 1997); e h) deficiência do potencial de crescimento do embrião (Nabors \& Lang, 1971).

Nascimento (1998), em um amplo estudo, procurou estabelecer uma relação entre a germinação das sementes de alface em altas temperaturas a diferentes tratamentos, como maturação de sementes, genótipos, vigor das sementes, condicionamento osmótico, e o uso de específicos reguladores de crescimento, como etileno. Recentemente, foram publicados diversos artigos evidenciando a existência de uma estreita relação entre o enfraquecimento do endosperma, a atividade da enzima endo-b-mananase, a produção de etileno, e a germinação das sementes de alface sob altas temperaturas (Nascimento et al, 1998a; 1999c; 2000b; Nascimento \& Cantliffe, 1999; Nascimento et al, 1999; Nascimento et al, 2000a; 2001; Cantliffe et al., 2000).

O embrião da semente de alface é totalmente envolvido pelo endosperma, o qual é constituído de uma camada de duas a quatro células. $\mathrm{O}$ endosperma pode atrasar ou prevenir a germinação das sementes atuando como uma barreira física à emissão da radícula, especialmente sob condições desfavoráveis. Assim, o "enfraquecimento" ("amolecimento") do endosperma torna-se um pré-requisito à emissão da radícula, sob condições de altas temperaturas (Sung, 1996). Uma vez que as paredes celulares do endosperma são compostas principalmente de polímeros de galactomananas, endo-b-mananase poderia ser uma enzima potencialmente regulatória no enfraquecimento do endosperma. O hormônio etileno poderia estar também envolvido neste processo, atuando diretamente no enfraquecimento do endosperma da semente através de um desconhecido mecanismo, ou estar envolvido na regulação de enzimas responsáveis pela "digestão" da parede celular do endosperma (por exemplo, endo-b-mananase), ou a combinação de ambos. Todos estes processos favoreceriam a emissão da radícula e consequentemente a germinação das sementes de alface sob altas temperaturas.

Testando diferentes genótipos, observou-se a exigência de uma menor força, no teste de puntuação, para penetrar o endosperma naquelas sementes provenientes de genótipos termo-tolerantes comparada com aqueles termosensitivos (Sung et al., 1998b). O mesmo foi observado em sementes osmoticamente condicionadas, isto é, um menor requerimento de força para penetrar o endosperma nessas sementes; alterações estruturais do endosperma na região da micrópila foram também observadas antes da emissão da radícula (Sung et al., 1998b). Isso sugere uma maior ou menor resistência do endosperma naquelas sementes que germinam satisfatoriamente ou não, respectivamente, em condições de altas temperaturas. Maior atividade da enzima endob-mananase no endosperma, antes da emissão da radícula, foi observada nessas situações onde as sementes germinaram adequadamente (Nascimento, 1998).

Em outro estudo, Nascimento et al. (2000a) verificaram que, em altas temperaturas, genótipos termo-tolerantes produziram maiores quantidades de 
etileno, apresentaram maior atividade de endo-b-mananase, e germinaram melhor do que aqueles genótipos termo-sensitivos. Em adição, sementes de genótipos termo-tolerantes embebidas a $35^{\circ} \mathrm{C}$ no escuro produziram menos etileno, apresentaram menor atividade enzimática e menor germinação do que aquelas sementes embebidas sob luz (Nascimento \& Cantliffe, 2000). Um inibidor de ação de etileno, tiossulfato de prata, inibiu ambos, etileno e endo-b-mananase, enquanto que o precursor de etileno, 1aminociclopropano-1- ácido carboxílico (ACC), induziu a atividade da enzima e permitiu a germinação das sementes do genótipo termo-sensitivo 'Dark Green Boston' (Nascimento et al., 1999c; Nascimento \& Cantliffe, 1999). Nascimento et al. (1999), avaliando diferentes níveis de vigor, observaram que sementes envelhecidas artificialmente, ou seja, de menor vigor, apresentaram menor produção de etileno e menor atividade enzimática do que aquelas não envelhecidas. Assim, o envelhecimento das sementes pode reduzir a produção de etileno e a atividade de endo-b-mananase, e assim, diminuir a germinação das sementes em condições de altas temperaturas. Todos esses resultados sugerem que o aumento de etileno e da atividade de endo-b-mananase podem contribuir para o enfraquecimento do endosperma, especialmente sob altas temperaturas, levando a uma condição de germinação. Esses resultados podem ser utilizados no estudo de marcadores moleculares para o desenvolvimento de cultivares tolerantes à germinação sob condições de altas temperaturas. O uso de alface como modelo neste estudo pode também ser aplicado e, ou estendido à outras espécies que apresentam problemas similares.

\section{LITERATURA CITADA}

BORTHWICK, H.A.; ROBINS, W.W. Lettuce seed and its germination. Hilgardia, v. 3, p. 275304, 1928.

BRADFORD, K.J. Germination improvement and avoidance of thermodormancy through osmotic treatment of seeds. Report to the California Iceburg Lettuce Advisory Board's Research Program, Annual Reports, 1984-1985, p. 61-72, 1985.

CANTLIFFE, D.J.; NASCIMENTO, W.M.; SUNG, Y.; HUBER, D.J. Lettuce endosperm weakening: a role for endo-b-mannanase in seed germination at high temperature. In: BLACK, M.; BRADFORD, K.J.; VÁSQUEZ-RAMOS, J., ed. Seed Biology: Advances and applications. Oxon: CABI, 2000. p. 277- 285.
CANTLIFFE, D.J.; SUNG,Y.; NASCIMENTO, W. M. Lettuce seed germination. Horticultural Reviews, v. 24, p.229-275, 2000.

DAMANIA, A.B. Inhibition of seed germination in lettuce at high temperature. Seed Research, v. 14, p. 177-184, 1986.

DREW, R.L.K.; BROCKLEHURST, P.A. Effects of temperature of mother-plant environment on yield and germination of seeds of lettuce (Lactuca sativa). Annals of Botany, v. 66, p. 63-71, 1990. DUTTA, S.; BRADFORD, K.J.; NEVINS, D.J. Endo-b-mannanase present in cell wall extracts of lettuce endosperm prior to radicle emergence. Plant Physiology, v. 133, p. 155-161, 1997.

FU, J.R.; YANG, S.F. Release of heat pretreatmnet-induced dormancy in lettuce seeds by ethylene or cytokinin in relation to the production of ethylene and the synthesis of 1aminocyclopropane-1-carboxylic acid during germination. Plant Growth Regulator, v. 2, p. 185192, 1983.

GRAY, D. Effects of temperature on the germination and emergence of lettuce (Lactuca sativa L.) varieties. HortScience, v. 50, p. 349361, 1975.

GRAY, D.; WURR, D.C.E.; WARD, J.A.; FELLOWS, J.R. Influence of post-flowering temperature on seed development, and subsequent performance of crisp lettuce. Annals of Applied Biology, v. 113, p. 391-402, 1988.

GUEDES, A.C.; CANTLIFFE, D.J. Germination of lettuce seeds at high temperature after seed priming. Journal of American Society for Horticultural Science, v. 105, p. 777-781, 1980. GUEDES, A.C.; CANTLIFFE, D.J.; NELL, T.A. Morphological changes during lettuce seed priming and subsequent radicle development. Journal of the American Society for Horticultural Science, v. 106, p. 121-126, 1981.

GUZMAN, V.L.; NAGATA, R.T.; DATNOFF, L.E.; RAID, R.N. 'Florida 202' and 'Everglades': New butterhead lettuce cultivars adapted to Florida. HortScience, v. 27, p. 852-853, 1992.

HARRINGTON, J.F.; THOMPSON, R.C. Effect of variety and area of production on subsequent germination of lettuce seed at high temperature. Proceedings of American Society for Horticultural Science, v. 59, p. 445-450, 1952.

HEYDECKER, W. Vigor. In: ROBERTS, E.H., ed. Viability of seeds. Syracuse: Syracuse University Press, 1972. p. 209-252.

IKUMA, H.; THIMANN, K.V. The role of seedcoats in germination of photosensitive Lettuce seeds. Plant Cell Physiology, v. 4, p. 169-185, 1963. KHAN, A.A. Hormonal regulation of primary and secondary seed dormancy. Israel Journal of Botany, v. 29, p. 207-224, 1980/81.

KHAN, A.A.; PRUSINSKI, J. Kinetin enhanced 1 -aminocyclopropane-1-carboxylic acid utilization during alleviation of high temperature stress in lettuce seeds. Plant Physiology, v. 91, p. 733-737, 1989.

MCWHA, J.A. Changes in abscisic acid levels during imbibition and germination of non-dormant and thermotolerant lettuce seeds. Australian Journal of Plant Physiology, v. 3, p. 849-851, 1976.

NABORS, M.W.; LANG, A. The growth physics and water relations of red-light-induced germination in lettuce seeds. I. Embryos germinating in osmoticum. Planta, v. 10, p. 1-25, 1971.
NASCIMENTO, W.M. Involvement of ethylene and endo-beta-mannanase in lettuce seed germination at high temperature. Gainesville: University of Florida, 1998. 138 p. (Tese doutorado).

NASCIMENTO, W.M. Envolvimento do etileno na germinação de sementes. Revista Brasileira de Fisiologia Vegetal, Londrina, vol. 12 (Edição especial), p. 163-174, 2000.

NASCIMENTO, W.M.; CANTLIFFE, D.J. Germination of primed lettuce seeds after storage. Proceedings of Florida State Horticultural Society, v. 111, p. 96-99, 1998.

NASCIMENTO, W.M.; CANTLIFFE, D.J Circunventing thermodormancy in lettuce. Acta Horticulturae, v. 504, p. 147-152, 1999.

NASCIMENTO, W.M.; CANTLIFFE, D.J. Produção de etileno, atividade de endo-b-mananase e germinação de sementes de alface em resposta a luz e temperatura. Revista Brasileira Sementes, Londrina, v. 22, n. 2, p. 1-5, 2000.

NASCIMENTO, W.M.; CANTLIFFE, D.J.; HUBER, D.J. Endo-b-mannanase activity and seed germination of thermosensitive lettuce genotype in response to temperature and seed priming. HortScience, v. 33, p. 542, 1998.

NASCIMENTO, W.M.; CANTLIFFE, D.J.; HUBER, D.J. Endo-b-mannanase activity during lettuce seed germination at high temperature conditions. Acta Horticulturae, v. 517, p. 107-111, 2000b.

NASCIMENTO, W.M.; CANTLIFFE, D.J.; HUBER, D.J. Endo-b-mannanase activity during lettuce seed germination at high temperature in response to ethylene. In: KANELLIS, A. K.; CHANG, C.; KLEE, H.; BLEECKER, A.B.; PECH, J.C.; GRIERSON, D., ed. Biology and biotechnology of the plant hormone ethylene II. Dordrecht: Kluwer Academic Publishers, 1999c., p. 191-192.

NASCIMENTO, W.M.; CANTLIFFE, D.J.; HUBER, D.J. Lettuce seed germination at high temperature: endo-beta-mannanase activity and ethylene production in response to seed vigor. In: INTERNATIONAL WORKSHOP ON SEED BIOLOGY, 6. 1999, Merida, Yucatan: Program and abstracts presentations... Merida, Yucatán: 1999a. p. 103.

NASCIMENTO, W.M.; CANTLIFFE, D.J.; HUBER, D.J. Lettuce seed germination and endob-mannanase are stimulated by ethylene. HortScience, v. 34, n. 3, p. 513, 1999 b.

NASCIMENTO, W.M.; CANTLIFFE, D.J.; HUBER, D.J. Thermotolerance in lettuce seeds: association with ethylene and endo-b-mannanase. Journal of the American Society for Horticultural Science, v. 125, n. 4, p. 518-524, 2000a.

NASCIMENTO, W.M.; CANTLIFFE, D.J.; HUBER, D.J. Endo-b-mannanase activity and seed germination of thermosensitive and thermotolerance lettuce genotypes in response to seed priming. Seed Science Research, v. 11, n. 3, p. $255-264,2001$.

SAINI, H.S.; CONSOLACION, E.D.; BASSI, P.K.; SPENCER, M.S. Requirement for ethylene synthesis and action during relief of thermoinhibition of lettuce seed germination by combinations of gibberellic acid, kinetin, and carbon dioxide. Plant Physiology, v. 81, p. 950953, 1986. 
SCHEIBE, J., LANG, A. Lettuce seed germination: Effects of high temperature and repeated far-red treatment in relation to phytochrome. Photochemistry and Photobiology, v. 9, p. 143-150, 1969.

SPEER, H.L. Some aspects of the function of the endosperm during the germination of lettuce seeds. Canadian Journal of Botany, v. 52, p. 1117-1121, 1974.

STEINER, J.J.; OPOKU-BOATENG. Natural season-long and diurnal temperature effects on lettuce seed production and quality. Journal of the American Society for Horticultural Science, v. 116, p. 396-400, 1991.
SUNG, Y. Identification and characterization of thermotolerance in lettuce seed germination. Gainesville: University of Florida, 1996. (Tese doutorado).

SUNG, Y.; CANTLIFFE, D.J.; NAGATA, R.T. Seed developmental temperature regulation of thermotolerance in lettuce. Journal of the American Society for Horticultural Science, v. 123, p. 700-705, 1998a.

SUNG, Y, CANTLIFFE, D.J.; NAGATA, R.T. Using a puncture test to identify the role of seed coverings on thermotolerant lettuce seed germination. Journal of the American Society for Horticultural Science, v. 123, p. 1102-1106, 1998b.
THOMPSON, P.A.; COX, S.A.; SANDERSON, R.H. Characterization of the germination responses to temperature of lettuce (Lactuca sativa L.) achenes. Annals of Botany, v. 43, p. 319-334 1979.

VALDES, V.M.; BRADFORD, K.J.; MAYBERRY, K.S. Alleviation of thermodormancy in coated lettuce seeds by seed priming. HortScience, v. 20, p. 1112-1114, 1985. WURR, D.C.E.; FELLOWS, J.R. The effects of grading and 'priming' seeds of crisp lettuce cv. Saladin, on germination at high temperature, seed 'vigour' and crop uniformity. Annals of Applied Biology, v. 105, p. 345-352, 1984.

SABÁ, R.T; LAMEIRA, O.A.; LUZ, J.M.Q.; GOMES, A.P.; INNECCO, R. Micropropagação do jaborandi. Horticultura Brasileira, Brasília, v. 20, n. 1, p. 106-109, março 2.002.

\title{
Micropropagação do jaborandi.
}

\author{
Renata Tuma Sabá1; Osmar Alves Lameira'; José Magno Queiroz Luz²; Ana Paula do Rosário Gomes; \\ Renato Innecco ${ }^{3}$ \\ ${ }^{1}$ Embrapa Amazônia Oriental, Travessa Dr. Enéas Pinheiro SN, 66.095-100 Belém-PA. E-mail:renata@hotmail.com; ${ }^{2}$ UFU-ICIAG, C. \\ Postal 593, 38.400-902 Uberlândia-MG; ${ }^{3}$ UFC-Dep. Fitotecnia, C. Postal 12.168, 60.356-001 Fortaleza-CE
}

\section{RESUMO}

O jaborandi (Pilocarpus microphyllus Stapf) é uma árvore da família Rutaceae destacando-se por intensivo uso na indústria farmacêutica através de um dos seus princípios ativos, pilocarpina, utilizado no controle do glaucoma. O objetivo do presente trabalho foi desenvolver um protocolo de micropropagação de jaborandi. Os ápices e segmentos caulinares utilizados na micropropagação foram retiradas das plântulas germinadas in vitro cultivadas em meio MS com diferentes concentrações e combinações de reguladores de crescimento. $\mathrm{O}$ tratamento com $3 \%$ de $\mathrm{NaOCl}$ (hipoclorito de sódio) e na ausência de $\mathrm{AG}_{3}$ (ácido giberélico) promoveu maior percentagem de germinação e menor índice de contaminação. O segmento apical foi o mais eficiente na emissão e comprimento médio de brotos de jaborandi sob diferentes concentrações de BAP (6benzilaminopurina) e diferentes combinações de zeatina e cinetina.

Palavras-chave: Pilocarpus microphyllus, Rutaceae, pilocarpina, reguladores de crescimento, in vitro.

\begin{abstract}
Micropropagation of the jaborandi.

The jaborandi (Pilocarpus microphyllus Stapf.) is a tree belonging to the Rutaceae family and is well known for its intensive use in the pharmaceutical industry through one of its most active principles, the pilocarpine, used to control glaucoma. The purpose of this research is to develop micropropagation protocols. Shoot tips and stem segments used in the micropropagation were removed from the seedlings grown in vitro and cultivated in MS medium with different concentrations and combinations of growth regulators. A treatment with $3 \%$ of $\mathrm{NaOCl}$ and the lack of $\mathrm{GA}_{3}$ caused a higher percentage of germination and a lower rate of contamination. The apical segment was the most efficient for shoot emission with best average length under different concentrations of BAP and different combinations of zeatin and kinetin.
\end{abstract}

Keywords: Pilocarpus microphyllus, Rutaceae, pilocarpine, growth regulators, in vitro.

(Aceito para publicação em 4 de dezembro de 2.001)

\begin{abstract}
A flora Amazônica é rica em espécies medicinais com grande potencial econômico para a extração de princípios ativos. Normalmente, as plantas medicinais desta região são exploradas através do extrativismo, o que aliado à expansão da fronteira agrícola na região, em áreas de populações de ocorrência natural dessas espécies, vem provocando erosão genética e colocando-as em risco de extinção.

Muitas espécies de ocorrência natural da região amazônica são largamente usa-
\end{abstract}

das na medicina popular. Dentre as espécies medicinais produtoras de princípios ativos de grande interesse mundial destaca-se o jaborandi, que é utilizado em produtos farmacológicos. Das folhas desta planta são extraídos sais de pilocarpina, um alcalóide utilizado na fabricação de um colírio indicado para o controle do glaucoma (Santos et al., 1988).

O jaborandi (Pilocarpus microphyllus Stapf) é uma planta arbustiva e bastante ramificada perten- cente à família Rutaceae, apresentando altura média de $2 \mathrm{~m}$, com folhas compostas medindo, em média, $40 \mathrm{~cm} \mathrm{e}$ folíolos coriáceos, de forma lanceolada. As flores são pequenas dispostas em rácimos (cachos) compactos. Os frutos são dispostos em cachos brancos contidos em cápsulas de córtex acinzentado e liso (Marques \& Costa, 1994). No Brasil, ocorre principalmente na região Leste da Amazônia e nas regiões do CentroSul e Nordeste (Marques \& Costa, 1994). 